\title{
Recenzenci 2014
}

W 2014 roku recenzentami prac nadesłanych do Nowotworów byli:

Prof. Włodzimierz Baranowski

Prof. Marek Bębenek

Prof. Wiesław Bonicki

Prof. Andrzej Borkowski

Prof. Krzysztof Bujko

Prof. Tomasz Demkow

Prof. Rafał Dziadziuszko

Dr Jan Gawełko

Prof. Krzysztof Herman

Dr hab. Stanisław Kłęk

Prof. Ireneusz Krasnodębski

Prof. Maciej Krzakowski

Prof. Anna Nasierowska-Guttmejer

Prof. Sergiusz Nawrocki

Prof. Anna Niwińska

\author{
Prof. Zbigniew Nowecki \\ Dr hab. Grzegorz Panek \\ Prof. Zygmunt Pojda \\ Prof. Piotr Potemski \\ Prof. Olgierd Rowiński \\ Prof. Marek Rusin \\ Dr hab. Janusz Skowronek \\ Prof. Andrzej Stelmach \\ Prof. Małgorzata Tacikowska \\ Prof. Edward Towpik \\ Prof. Krzysztof Urbański \\ Prof. Marzena Wełnicka-Jaśkiewicz \\ Prof. Romuald Zdrojowy \\ Dr Maria Zwierko
}

Wszystkim składam serdeczne podziękowania za pomoc w redagowaniu pisma.

Prof. Edward Towpik 